\title{
SIKAP, MINAT DAN MOTIVASI MURID MELANAU DALAM PEMBELAJARAN BAHASA MELAYU SEBAGAI BAHASA KEDUA
}

\author{
Attitudes, Interests and Motivation of Melanau Students in Learning Malay Language as a \\ Second Language
}

Nancy anak Ngumbang

prestylianaen@gmail.com

Zamri Mahamod

d-zam@ukm.edu.my

\begin{abstract}
SMK. Toh Puan Datuk Patinggi Hajah Normah, Kementerian Pendidikan Malaysia Universiti Kebangsaan Malaysia
\end{abstract}

\begin{abstract}
ABSTRAK
Kajian ini bertujuan untuk mengenal pasti sikap, minat dan motivasi murid Melanau dalam pembelajaran Bahasa Melayu sebagai bahasa kedua. Kajian ini dilaksanakan berdasarkan Model Socio-educational oleh Gardner (1985). Sikap ditinjau daripada aspek sikap terhadap penutur Bahasa Melayu, sikap integratif terhadap Bahasa Melayu dan minat terhadap Bahasa Melayu. Motivasi pula ditinjau daripada aspek motivasi intrinsik dan motivasi ekstrinsik dalam mempelajari Bahasa Melayu. Kajian berbentuk tinjauan ini telah dibuat terhadap 242 orang murid tingkatan 4 dan 5 di dua buah sekolah menengah di daerah Matu dan Daro, Sarawak sebagai responden kajian. Data diperoleh melalui instrumen soal selidik. Data dianalisis secara statistik deskriptif. Hasil kajian menunjukkan bahawa sikap, minat dan motivasi murid Melanau dalam pembelajaran Bahasa Melayu sebagai bahasa kedua adalah tinggi. Muridmurid Melanau ini mempunyai sikap positif terhadap pembelajaran Bahasa Melayu. Mereka juga berminat mempelajari Bahasa Melayu, manakala motivasi mereka ketika belajar Bahasa Melayu juga adalah tinggi. Implikasi kajian ini ialah mata pelajaran Bahasa Melayu diakui penting oleh murid-murid Melanau ini sebagai bahasa ilmu, bahasa kebangsaan dan perpaduan negara Malaysia.
\end{abstract}

Kata kunci: sikap; minat; motivasi; murid Melanau; Bahasa Melayu; bahasa kedua

\begin{abstract}
This study aims to identify the attitude and motivation of Melanau students in learning the Malay language as a second language. This study was conducted based on the Socio-educational model by Gardner (1985).The study also aims to assess the differences in attitude and motivation of Melanau students in learning the Malay language as a second language based on gender, form and class streaming, as well as identifying the relationship between attitude and motivation of students in learning Malay language with their families' socioeconomic status. This is a survey research and a total of 242 Form Four and Five students in two schools in Matu and Daro area have responded. Data were collected through questionnaires. Data were analyzed by descriptive statistics and inferential statistical t-test and Pearson correlation. The attitudes observed for this study involved students' attitude towards speakers of Malay language, integrative attitude towards Malay language and interest in the language. Meanwhile, the aspect of motivation was evaluated in terms of intrinsic motivation and extrinsic motivation in studying Malay language. The results showed that there was no significant difference between the attitude and motivation of Melanau students in learning Malay language as a second language based on gender and form, but the difference existed based on class streaming. The results also showed a significant relationship between Melanau students' attitude and motivation in learning Malay language with their families' socioeconomic status. Based on these findings, the researchers made several proposals in the study relating to the attitude and motivation of students in learning Malay language.
\end{abstract}

Keywords: Attitude; motivation; Melanau students; Malay language; second language 


\section{PENGENALAN}

Sikap dan motivasi sangat signifikan dalam mempelajari bahasa kedua. Sikap dan motivasi bergerak seiring dalam proses mencapai sesuatu matlamat. Dalam pembelajaran bahasa Melayu oleh murid bukan Melayu, sikap dan tahap motivasi menentukan tahap penguasaan bahasa Melayu sebagai bahasa kedua. Tahap motivasi juga menentukan seseorang yang bukan penutur jati bahasa Melayu menaruh minat menguasai bahasa Melayu. Selain itu, sikap juga mempunyai pengaruh yang dinamik terhadap tindak balas seseorang. Sikap dan motivasi seiring dalam pembelajaran bahasa Melayu sebagai bahasa kedua. Hal ini demikian kerana dalam pembelajaran bahasa Melayu sebagai bahasa kedua oleh murid bukan Melayu, sikap dan motivasi adalah usaha yang disedari oleh mental untuk menggerakkan, menggarahkan dan menjaga tingkah laku seseorang supaya terdorong untuk bertindak melakukan sesuatu sehingga mencapai hasil atau tujuan pembelajaran bahasa kedua.

Zamri dan Mohamed Amin (2005) dalam kajian mereka mendapati bahawa faktor sikap merupakan sebahagian daripada faktor penyumbang kepada kemerosotan pencapaian murid dalam Bahasa Melayu. Zamri dan Mohamed Amin Embi (2006) juga mendapati murid bukan Melayu mempunyai sikap yang negatif dan kurang berminat untuk mempelajari bahasa Melayu dalam kajian mereka. Jerie dan Zamri (2011) juga membuktikan murid Iban di daerah Kanowit, Sarawak mempunyai sikap yang positif dan motivasi yang tinggi sewaktu mempelajari bahasa Melayu sebagai kedua bahasa dalam kajian mereka.

Kajian oleh Abdul Rasid (2010) juga mendapati bahawa murid Cina mempelajari Bahasa Melayu atas sebab Bahasa Melayu merupakan mata pelajaran yang diwajibkan. Seandainya, mata pelajaran Bahasa Melayu tidak diwajibkan, kemungkinan mereka tidak akan mempelajari Bahasa Melayu. Dapatan kajian Abdul Rasid (2010) ini juga mendapati murid Cina kurang bermotivasi untuk mempelajari Bahasa Melayu kerana mereka merasakan Bahasa Melayu sebagai satu mata pelajaran yang susah dan mengelirukan. Oleh yang demikian, dapatlah disimpulkan bahawa motivasi mempengaruhi murid Cina dalam mempelajari mata pelajaran Bahasa Melayu. Siti Salwah dan Jamaluddin (2013) dalam kajian mereka juga membuktikan bahawa sikap dan motivasi murid peralihan yang terdiri daripada kaum Cina dan India mempelajari bahasa Melayu sebagai bahasa kedua adalah positif dan tinggi motivasinya apabila wujud ganjaran untuk setiap aktiviti yang berjaya dilakukan oleh mereka dalam pembelajaran bahasa kedua.

Kajian ini juga penting kerana tindakan susulan dalam usaha meningkatkan pencapaian Bahasa Melayu dalam peperiksaan awam dapat dilakukan dengan berkesan kerana punca kemerosotan pencapaian bahasa Melayu juga disebabkan oleh faktor-faktor lain. Hal ini dikatakan demikian kerana sikap dan motivasi hanya salah satu daripada faktor penyebabnya. Seandainya tindakan susulan yang digariskan sesuai dalam usaha mengatasi faktor utama yang menyebabkan permasalahan ini, maka bahasa Melayu dapat dipelajari dengan baik dalam kalangan rakyat di negara ini, terutama murid bukan Melayu.

\section{PERNYATAAN MASALAH}

Merapatkan jurang pendidikan dalam kalangan masyarakat berbilang kaum atau etnik yang pelbagai merupakan agenda pendidikan negara. Perkara yang menjadi fokus kajian ini ialah sikap murid dan tahap motivasi murid bukan Melayu mempelajari bahasa Melayu yang merupakan bahasa kedua mereka. Kajian yang dilakukan akan meninjau sikap dan tahap motivasi murid Melanau dalam pembelajaran bahasa kedua. Selain itu, belum ada lagi kajian berkaitan sikap dan motivasi dalam pembelajaran Bahasa Melayu sebagai bahasa kedua oleh murid Melanau dijalankan sehingga kajian dijalankan.

Pencapaian mata pelajaran wajib lulus seperti Bahasa Melayu pada peringkat Sijil Peperiksaan Malaysia (SPM) telah mendapat perhatian pelbagai pihak di sekolah seperti, pentadbir, guru-guru dan murid-murid. Perkara ini dikatakan demikian kerana kepujian dalam Bahasa Melayu merupakan syarat am bagi seseorang murid diterima masuk ke pusat-pusat pengajian yang lain. Walau bagaimanapun, pencapaian Bahasa Melayu SPM yang menunjukkan penurunan telah membimbangkan semua pihak. Ramai beranggapan bahawa sikap negatif dan tahap motivasi yang rendah dalam diri murid bukan Melayu dalam proses mempelajari Bahasa Melayu dilihat sebagai faktor penyebab yang menyumbang kepada permasalahan ini. 
Tahap motivasi murid yang agak rendah juga menjadi penyumbang kepada penguasaan bahasa Melayu dalam kalangan murid Melanau kurang memuaskan. Tahap motivasi murid dapat ditingkatkan jika mereka sering berusaha dan bertekad untuk berjaya dalam penguasaan bahasa Melayu sebagai bahasa kedua. Kenyataan ini bersesuaian dengan definisi motivasi yang telah diberikan oleh Zamri (2016), iaitu motivasi bermaksud hasrat yang diusahakan supaya objektif pembelajaran tercapai. Dorongan dan galakan yang bersifat dalaman dan luaran amat penting kepada murid ketika mempelajari bahasa kedua.

Pembelajaran bahasa Melayu sebagai bahasa kedua memang wajar dikuasai. Cabaran utama kepada murid dalam mempelajari bahasa Melayu ialah bentuk soalan yang dikemukakan menguji kemahiran berfikir aras tinggi murid. Kerisauan tidak dapat lulus sering menghantui murid kerana subjek Bahasa Melayu wajib lulus pada peringkat SPM. Pengukuran penguasaan bahasa Melayu dinilai melalui gred mata pelajaran. Pencapaian gred D dan E dalam mata pelajaran Bahasa Melayu menunjukkan tahap penguasaan bahasa Melayu atau bahasa kedua yang minimum. Kemerosotan pencapaian Bahasa Melayu 2015 (LPM 2015) menjadi mimpi ngeri apabila pencapaian cemerlang dalam mata pelajaran Bahasa Melayu merosot. Jadi, kajian ini dilihat sangat penting untuk membuktikan kebenaran bahawa sikap dan motivasi sebagai punca utama permasalahan ini. Kajian yang dijalankan adalah untuk mengetahui sikap serta mengenal pasti tahap motivasi murid Melanau menengah atas di daerah Matu dan Daro dalam pembelajaran bahasa kedua, iaitu bahasa Melayu.

Secara keseluruhan, kajian yang dijalankan penting kepada semua pihak. Generasi murid bersikap positif dan bermotivasi tinggi dalam pembelajaran sudah semestinya berjaya dalam pelajaran. Setelah mereka berjaya dalam pelajaran, maka mereka juga berjaya dalam bidang-bidang lain dan akhirnya berupaya menyumbang sesuatu yang berharga kepada negara. Generasi muda merupakan permata negara yang harus dibentuk dengan sikap yang positif melalui pemupukan nilai murni. Pembentukan generasi yang kaya dengan nilai baik ini akan membawa kecemerlangan kepada negara pada masa depan.

\section{TUJUAN DAN OBJEKTIF KAJIAN}

Tujuan kajian ini adalah untuk mengetahui sikap dan motivasi murid Melanau di daerah Matu dan Daro dalam pembelajaran bahasa Melayu sebagai bahasa kedua mereka. Secara khusus, objektif kajian ini adalah untuk:

1. Mengetahui tahap sikap murid Melanau dalam pembelajaran bahasa Melayu sebagai bahasa kedua.

2. Mengenal pasti tahap motivasi murid Melanau dalam pembelajaran bahasa Melayu sebagai bahasa kedua.

\section{DEFINISI OPERASIONAL}

Secara umum, sikap boleh didefinisikan sebagai kesediaan mental secara neutral yang tersusun melalui pengalaman, dan mempunyai pengaruh yang dinamik terhadap tindak balas seseorang. Zamri, Ruslin dan Mohamed Amin (2015) serta Zamri (2016) mengatakan bahawa sikap ialah tindak balas seseorang yang dipengaruhi oleh emosi ketika berinteraksi dengan seseorang atau cara-cara yang ditunjukkan oleh seseorang ketika menghadapi sesuatu. Sikap melibatkan satu sistem penilaian yang positif dan negatif, baik atau buruk dan bersabit dengan objek sosial, selain sikap terbentuk berasaskan faktor-faktor seperti desakan dalaman, tabiat yang dipelajari dan pengaruh persekitaran. Sikap dalam kajian ini bermaksud pemikiran, perasaan atau tanggapan terhadap sesuatu perkara yang boleh mendorong murid-murid Melanau mempelajari Bahasa Melayu mengikut konteks atau keadaan seperti mengikut jantina, aliran kelas ataupun tingkatan.

Zamri (2016) mendefinisikan motivasi sebagai gabungan usaha dan hasrat untuk mencapai matlamat belajar bahasa. Hal ini bererti motivasi untuk belajar bahasa kedua dilihat sebagai usaha dan kegigihan seseorang untuk mempelajari sesuatu bahasa. Motivasi yang dimaksudkan dalam kajian ini ialah motivasi integratif dan motivasi instrumental. Dalam kajian ini, berdasarkan motivasi integratif, tujuan murid Melanau dalam pembelajaran bahasa kedua, iaitu Bahasa Melayu dengan tujuan ingin berkongsi ciri-ciri komunikasi bahasa Melayu dan menganggap dirinya berkemungkinan menjadi ahli 
komuniti Melayu. Motivasi instrumental dalam kajian ini hanya melihat pembelajaran bahasa Melayu sebagai bahasa kedua dalam kalangan murid Melanau sebagai suatu yang dapat menguntungkan mereka tanpa dapat melibatkan diri dengan komuniti Melayu atau kebudayaan bahasa Melayu yang dipelajarinya. Keuntungan yang dimaksudkan ialah motivasi instrumental yang dimiliki lebih bersifat ganjaran, iaitu mempelajari bahasa kedua dengan baik agar dapat meningkatkan prestasi kerja dan pendidikannya. Dengan ini, ternyata motivasi integratif bersifat kekal dan relevan dengan pencapaian bahasa kedua berbanding dengan motivasi instrumental yang banyak dipengaruhi faktor luaran seperti ganjaran. Dalam kajian ini, motivasi ekstrinsik dan motivasi intrinsik murid Melanau dalam pembelajaran Bahasa Melayu sebagai bahasa kedua akan dikupas dengan lebih jelas dan berfokus berdasarkan saranan pengkaji yang terdahulu.

Berdasarkan Kamus Dewan Edisi Keempat (2014), murid bermaksud orang atau anak yang sedang belajar atau berguru, pelajar atau penuntut. Murid bermaksud orang yang belajar (seperti murid sekolah, penuntut di maktab dan sebagainya), atau orang yang mengaji (menyelidiki ilmu). Melanau pula bermaksud suku kaum peribumi di Sarawak yang tinggal di persisiran pantai, muara dan anak sungai Rejang, terutamanya di daerah Matu dan Daro, Dalat, Mukah, Bintulu dan Miri. Dalam kajian ini, murid Melanau ialah murid tingkatan 4 dan 5 yang sedang belajar di dua buah sekolah menengah kebangsaan di daerah Matu dan Daro, Sarawak.

\section{KERANGKA TEORI KAJIAN}

Kerangka teori kajian ini adalah berdasarkan teori pemerolehan bahasa Model Sosioeducational oleh Gardner (1985). Berdasarkan model ini, Gardner telah menggunakan satu alat pengukuran sikap dan motivasi yang diberi nama "The Attitude / Motivation Test Battery (AMBT). Model ini menjelaskan sikap dan motivasi murid terhadap bahasa kedua dipengaruhi oleh ciri-ciri sosial yang terdapat di sekitarnya. Murid yang berbeza latar belakang keluarga dan masyarakat akan mempamerkan sikap yang berbeza terhadap bahasa asing. Dalam erti kata yang lain, latar belakang keluarga dan masyarakat bermaksud persekitaran sosial yang merujuk kepada suasana tempat pembelajaran bahasa kedua berlaku.

Selain itu, sikap merangkumi perasaan, kepercayaan dan pemikiran terhadap sesuatu objek. Oleh yang demikian, tindak balas seseorang didorong oleh fikiran, perasaan atau tanggapan terhadap sesuatu objek atau aspek. Namun, tindak balas seseorang akan mempengaruhi motivasi yang ada pada dirinya. Zamri (2016) bersetuju bahawa sikap murid mempengaruhi motivasi pembelajaran bahasa kedua selain faktor guru, ibu bapa, rakan sebaya dan penutur jati sesuatu bahasa. Zamri (2016) tidak menafikan sikap mempunyai hubungan yang erat dengan motivasi selain bakat bahasa yang sedia ada dalam kalangan murid, malahan pencapaian gred murid juga dipengaruhi sikap dan motivasi. Hal ini dapat dibuktikan apabila wujud pertalian yang jelas antara sikap integratif dan motivasi integratif dengan bebarapa aspek pencapaian bahasa asing dalam kajian mereka.

Dalam konteks pemerolehan bahasa, iaitu pembelajaran bahasa kedua iaitu Bahasa Melayu oleh murid Melanau, pemerolehan bahasa kedua akan berlaku secara formal dan secara tidak formal. Pemerolehan bahasa secara formal merujuk kepada pembelajaran yang terancang, contohnya pembelajaran Bahasa Melayu di dalam bilik darjah, manakala pemerolehan bahasa kedua secara informal merujuk kepada situasi pembelajaran melalui pengalaman.

\section{METODOLOGI}

Dalam kajian kuantitatif dengan menggunakan instrumen soal selidik ini keseluruhan individu dalam populasi akan diambil sebagai 'target population'. Hal ini dikatakan demikian kerana kajian yang baik ialah kajian yang menggunakan populasi sebagai sampel kajian atau dengan mengambil sebanyakbanyaknya sampel yang menghampiri jumlah dalam populasinya. Populasi dalam kalangan murid diambil daripada dua sekolah menengah kebangsaan di Daro dan Matu, Sarawak. Murid-murid terdiri daripada murid tingkatan empat dan lima yang belajar di aliran Sains dan Sastera. Berdasarkan rumus yang telah dikemukakan oleh mengikut Krejcie dan Morgan (1970), sampel kajian seramai 242 orang murid telah 
diambil daripada 686 murid tingkatan empat dan lima di kedua-dua sekolah menengah kebangsaan daerah Daro dan Mato tersebut. Semua 242 orang murid ini terdiri daripada murid lelaki dan murid perempuan.

Instrumen kajian ini ialah soal selidik tentang sikap dan motivasi murid Melanau dalam pembelajaran bahasa Melayu sebagai bahasa kedua telah dibahagikan kepada dua bahagian, iaitu Bahagian A tentang maklumat responden dan Bahagian B tentang sikap dan motivasi murid Melanau dalam pembelajaran bahasa Melayu sebagai bahasa kedua. Bahagian maklumat responden mengandungi enam item seperti jantina, tingkatan, aliran kelas, tahap pendidikan ibu bapa atau penjaga responden, pekerjaan ibu bapa atau penjaga responden, dan pendapatan ibu bapa atau penjaga responden

Bahagian B mengandungi dua aspek seperti butiran sikap mempelajari bahasa yang mengandungi 14 soalan dan butiran motivasi mempelajari Bahasa Melayu yang mengandungi dua bahagian, iaitu motivasi intrinsik yang mengandungi 12 soalan dan motivasi ekstrinsik 11 soalan diubah sesuai daripada kajian Jerie dan Zamri (2011).

Instrumen kajian yang dibentuk untuk melihat sikap dan motivasimurid Melanau dalam pembelajaran bahasa Melayu sebagai bahasa kedua ialah skala Likert 5 mata dengan skor 1, 2, 3, 4 dan 5 . Skor bagi sikap dan motivasimurid Melanau dalam pembelajaran Bahasa Melayu sebagai Bahasa Kedua dikodkan mengikut skala yang sesuai untuk melihat setiap aspek dalam item yang dikemukakan. Skor min yang dirujuk daripada Tschannen-Moran, dan Garies (2004) seperti dalam Jadual 1.

JADUAL 1 Min skala lima Likert mengikut lima tahap

\begin{tabular}{cc}
\hline Nilai Min & Interpretasi \\
\hline $1.00-1.80$ & Sangat Rendah \\
$1.81-2.60$ & Rendah \\
$2.61-3.40$ & Sederhana \\
$3.41-4.20$ & Tinggi \\
$4.21-5.00$ & Sangat Tinggi \\
\hline
\end{tabular}

Sumber: Tschannen-Moran, M \& Garies, C.R. (2004)

Seramai 30 orang responden di SMK Toh Puan Datuk Patinggi Hajjah Normah, Daro telah dipilih untuk menjalani ujian rintis menggunakan instrumen ini. Responden yang dipilih adalah dalam kalangan murid tingkatan empat dan tingkatan limayang berlainan jantina, aliran kelas dan latar belakang sosioekonomi keluarga. Sepanjang proses memasukkan data dalam sistem SPSS beberapa kekurangan, kesilapan dan kelemahan pada soal selidik telah dibaiki sebelum diedarkan kepada populasi kajian.

JADUAL 2 Kebolehpercayaan instrumen kajian

\begin{tabular}{|c|c|c|c|}
\hline Bil. & Pemboleh Ubah & $\begin{array}{l}\text { Nilai Alpha } \\
\text { Cronbach }\end{array}$ & $\begin{array}{l}\text { Alpha Cronbach } \\
\text { Keseluruhan }\end{array}$ \\
\hline 1 & $\begin{array}{l}\text { Sikap murid Melanau terhadap penutur bahasa } \\
\text { Melayu }\end{array}$ & 0.851 & \multirow{5}{*}{0.949} \\
\hline 2 & $\begin{array}{l}\text { Sikap integratif murid Melanau terhadap bahasa } \\
\text { Melayu }\end{array}$ & 0.506 & \\
\hline 3 & Minat murid Melanau terhadap bahasa Melayu & 0.890 & \\
\hline 4 & $\begin{array}{l}\text { Motivasi intrinsik murid Melanau dalam } \\
\text { mempelajari bahasa Melayu }\end{array}$ & 0.909 & \\
\hline 5 & $\begin{array}{l}\text { Motivasi ekstrinsik murid Melanau mempelajari } \\
\text { bahasa Melayu }\end{array}$ & 0.871 & \\
\hline
\end{tabular}

Data yang diperoleh daripada kajian rintis telah menunjukkan nilai Alpha Croncbach yang tinggi. Sekaran (2000) menyatakan nilai Alpha Cronbach menghampiri nilai 1.0, kebolehpercayaan item adalah tinggi dan baik. Jadual 2 menunjukkan bahawa setiap pemboleh ubah yang dikaji mempunyai kebolehpercayaan yang tinggi dan layak digunakan dalam kajian sebenar. Nilai Alpha Croncbach bagi setiap pemboleh ubah tersebut ialah sikap murid Melanau terhadap penutur bahasa Melayu (0.851), sikap 
integratif murid Melanau terhadap bahasa Melayu (0.506), minat murid Melanau terhadap bahasa Melayu (0.890), motivasi intrinsik murid Melanau dalam mempelajari bahasa Melayu (0.909) dan motivasi ekstrinsik murid Melanau mempelajari bahasa Melayu (0.871). Secara keseluruhan, nilai Alpha Cronbach bagi instrumen sikap dan motivasi murid Melanau dalam pembelajaran bahasa Melayu sebagai bahasa kedua adalah tinggi, iaitu (0.949) dan instrumen ini kukuh dan kekal digunakan dalam kajian sebenar.

Data yang diperoleh melalui kajian ini telah dianalisis dengan menggunakan program 'Statistical Package for Social Science (SPSS). Kaedah statistik deskriptif dan statistik inferensi digunakan untuk menganalisis data dalam kajian ini. Data kuantitatif lebih mudah diukur dan diterangkan menggunakan statistik deskriptif Statistik deskriptif yang digunakan ialah dalam bentuk taburan kekerapan, peratusan, min, mod, median dan sisihan piawai. Pengujian tentang perbezaan min sikap dan motivasi dalam pembelajaran bahasa Melayu dalam kalangan murid Melanau antara jantina, tingkatan dan aliran kelas di sekolah menengah kebangsaan di daerah Matu dan Daro, dibuat menggunakan ujian-t. Aras signifikan yang digunakan dalam kajian ini adalah pada aras kebarangkalian $95 \%(\mathrm{p}<0.05)$.

\section{DAPATAN KAJIAN}

\section{Ciri Demografi Responden}

Bahagian ini membincangkan maklumat demografi responden kajian. Daripada Jadual 3, didapati bilangan responden lelaki adalah 112 orang atau $46.28 \%$ (\%), manakala responden perempuan ialah 130 orang atau 53.72\%.Dapatan ini menunjukkan bilangan murid perempuan adalah melebihi daripada murid lelaki. 122 orang atau 50.42\% responden adalah daripada SMK Matu, manakala reponden di SMK Toh Puan Datuk Patinggi Hajjah Normah sebanyak $49.58 \%$ atau 120 orang. Bilangan responden di tingkatan empat ialah 108 orang atau 44.63\%, manakala responden di tingkatan lima ialah 134 orang atau 55.37\%. Dapatan ini menunjukkan bilangan murid tingkatan lima adalah melebihi daripada murid tingkatan empat. 65 orang atau $26.86 \%$ responden adalah daripada aliran sains, manakala reponden daripada aliran sastera sebanyak $73.14 \%$, iaitu seramai 177 orang.

Selain itu, daripada 242 orang responden kajian, 68 orang atau $28.1 \%$ ibu bapa atau penjaga mempunyai tahap pendidikan peringkat UPSR, manakala 48 orang atau $19.8 \%$ ibu bapa atau penjaga murid mempunyai tahap pendidikan peringkat PMR, dan SPM sebanyak $43.0 \%$ (104 orang) selain 4 orang responden ibu bapa atau penjaganya mempunyai tahap pendidikan pada peringkat STPM (1.7\%). Ibu bapa atau penjaga yang mempunyai tahap pendidikan pada peringkat sijil/diploma ialah sebanyak 8 orang $(3.3 \%)$ dan peringkat ijazah ialah sebanyak 10 orang iaitu $4.1 \%$.

Sehubungan dengan itu, daripada 242 orang responden kajian, 21 orang atau $8.7 \%$ ibu bapa atau penjaga mereka tidak bekerja, manakala 22 orang atau $9.1 \%$ petani dan nelayan sebanyak $6.6 \%$ (16 orang), 107 (44.2\%) orang responden ibu bapa atau penjaganya adalah buruh, 24 orang ibu bapa atau penjaga responden bekerja sendiri, dan sebanyak 52 orang ibu bapa atau penjaga responden bekerja dalam bidang kerajaan kerajaan iaitu sebanyak 21.5.

Berkaitan dengan kadar pendapatan ibu bapa atau penjaga responden daripada 242 orang responden kajian, seramai 194 orang atau $80.2 \%$ responden berlatarbelakangkan keluarga yang berpendapatan antara RM800 hingga RM1200. Manakala 19 orang atau $7.9 \%$ daripada responden yang dikaji mempunyai keluarga yang berpendapatan antara RM1300 hingga RM1900, 11 orang (4.5 \%) responden yang dikaji mempunyai keluarga yang berpendapatan antara RM2000 hingga RM2900, dan 18 orang ( $7.4 \%)$ responden yang dikaji mempunyai keluarga yang berpendapatan antara RM3000 ke atas.

JADUAL 3 Taburan sampel mengikut jantina, sekolah, tingkatan dan aliran kelas

\begin{tabular}{lccc}
\hline & Perkara & Bilangan & \% \\
\hline Jantina & & & \\
Lelaki & & 112 & 46.28 \\
Perempuan & & 130 & 53.72 \\
\hline Sekolah & 122 & 50.42 \\
SMK Matu & & \multicolumn{2}{c}{}
\end{tabular}




\begin{tabular}{|c|c|c|}
\hline SMK Toh Puan Datuk Patinggi Hajjah Normah & 120 & 49.58 \\
\hline \multicolumn{3}{|l|}{ Tingkatan } \\
\hline Empat & 108 & 44.63 \\
\hline Lima & 134 & 53.37 \\
\hline \multicolumn{3}{|l|}{ Aliran } \\
\hline Sains & 65 & 26.86 \\
\hline Sastera & 177 & 73.14 \\
\hline \multicolumn{3}{|l|}{ Tahap Pendidikan Ibu Bapa/Penjaga } \\
\hline UPSR & 68 & 28.1 \\
\hline PMR & 48 & 19.8 \\
\hline SPM & 104 & 43.0 \\
\hline STPM & 4 & 1.7 \\
\hline Sijil/Diploma & 8 & 3.3 \\
\hline Ijazah & 10 & 4.1 \\
\hline \multicolumn{3}{|l|}{ Pekerjaan } \\
\hline Tidak Bekerja & 21 & 8.7 \\
\hline Petani & 22 & 9.1 \\
\hline Nelayan & 16 & 6.6 \\
\hline Buruh & 107 & 44.2 \\
\hline Bekerja Sendiri & 24 & 9.9 \\
\hline Kakitangan Kerajaan & 52 & 21.5 \\
\hline \multicolumn{3}{|l|}{ Pendapatan } \\
\hline RM800-RM1200 & 194 & 80.2 \\
\hline RM1300-RM1900 & 19 & 7.9 \\
\hline RM2000-RM2900 & 11 & 4.5 \\
\hline RM3000 ke atas & 18 & 7.4 \\
\hline Jumlah & 242 & 100.0 \\
\hline
\end{tabular}

\section{Sikap Murid Melanau Terhadap Penutur Bahasa Melayu}

Jadual 4 menunjukkan analisis terperinci terhadap item dalam sikap murid Melanau terhadap penutur bahasa Melayu. Daripada analisis yang dibuat didapati min dan sisihan piawai keseluruhan ditunjukkan ialah $3.949(\mathrm{~m}=3.949)$ dan $0.773(\mathrm{sp}=0.773)$ yang menunjukkannya berada pada tahap yang tinggi. Min yang tertinggi ialah 4.21 berada pada tahap yang sangat tinggi dengan sisihan piawai 0.925 , iaitu $49.6 \%$ responden kajian mengatakan bahawa mereka selalu berasa seronok berkenalan dengan orang Melayu.

JADUAL 4 Taburan min bagi item berkaitan sikap murid terhadap penutur bahasa Melayu

\begin{tabular}{llcc}
\hline \multicolumn{1}{c}{ Item } & Min & $\begin{array}{c}\text { Sisihan } \\
\text { Piawai }\end{array}$ \\
\hline 1. & Saya suka orang Melayu. & 4.09 & 1.053 \\
2. & Saya seronok berkenalan dengan orang Melayu. & 4.21 & 0.925 \\
3. & Orang Melayu suka bergaul dengan orang lain. & 3.94 & 0.936 \\
4. Orang Melayu bertimbang rasa. & 3.95 & 0.952 \\
5. & Orang Melayu boleh dipercayai. & 3.56 & 1.042 \\
\hline \multicolumn{1}{c}{ Purata } & $\mathbf{3 . 9 4 9}$ & $\mathbf{0 . 7 7 3}$ \\
\hline
\end{tabular}

\section{Sikap Integratif Murid Melanau Terhadap Bahasa Melayu}

Jadual 5 menunjukkan analisis terperinci tentang item-item sikap integratif murid Melanau terhadap bahasa Melayu. Daripada analisis yang dibuat didapati min dan sisihan paiwai keseluruhan yang ditunjukkan ialah $3.905(\mathrm{~m}=3.905)$ dan $1.023(\mathrm{sp}=1.023)$ dan ia berada pada tahap tinggi. Min yang tertinggi ialah 3.92 berada pada tahap yang tinggi dengan sisihan piawai 2.179 iaitu $34.3 \%$ responden kajian mengatakan bahawa mereka selalu mempunyai perasaan ingin mempunyai hubungan dengan orang 
Melayu. Ini menunjukkan bahawa mereka mempunyai sikap integratif yang tinggi terhadap bahasa Melayu.

JADUAL 5 Taburan min bagi item sikap integratif murid Melanau terhadap bahasa Melayu

\begin{tabular}{cccc}
\hline & Item & Min & $\begin{array}{c}\text { Sisihan } \\
\text { Piawai }\end{array}$ \\
\hline 6. & Saya ingin mempunyai hubungan dengan orang Melayu. & 3.92 & 2.179 \\
7. Saya fasih Bahasa Melayu jika bergaul dengan orang Melayu. & 3.90 & 0.990 \\
8. Saya ingin tahu dengan mendalam tentang orang Melayu. & 3.90 & 1.018 \\
\hline Purata & $\mathbf{3 . 9 0 5}$ & $\mathbf{1 . 0 2 3}$ \\
\hline
\end{tabular}

\section{Minat Murid Melanau Terhadap Bahasa Melayu}

Jadual 6 menunjukkan analisis terperinci tentang item minat murid Melanau terhadap bahasa Melayu. Daripada analisis yang dibuat didapati min dan sisihan paiwai keseluruhan yang ditunjukkan ialah 4.199 $(\mathrm{m}=4.199)$ dan $0.705(\mathrm{sp}=0.705)$ dan berada pada tahap tinggi. Min yang tertinggi ialah 4.43 dan berada pada tahap yang sangat tinggi dengan sisihan piawai 0.798 iaitu $60.3 \%$ responden kajian mengatakan bahawa mereka selalu bersungguh-sungguh belajar bahasa Melayu. Hal ini menunjukkan bahawa mereka mempunyai minat yang sangat tinggi terhadap bahasa Melayu.

JADUAL 6 Taburan min bagi item minat murid Melanau terhadap bahasa Melayu

\begin{tabular}{lcc}
\hline \multicolumn{1}{c}{ Item } & Min & $\begin{array}{c}\text { Sisihan } \\
\text { Piawai }\end{array}$ \\
\hline 9. Saya bersungguh-sungguh belajar Bahasa Melayu. & 4.43 & 0.798 \\
10. Saya minat belajar Bahasa Melayu. & 4.38 & 0.792 \\
11. Saya menumpukan perhatian di dalam kelas Bahasa Melayu. & 4.14 & 0.870 \\
12. Saya sentiasa menyiapkan kerja rumah Bahasa Melayu. & 3.91 & 0.911 \\
13. Saya suka mata pelajaran Bahasa Melayu. & 4.26 & 0.841 \\
14. Saya tertarik hati dengan mata pelajaran Bahasa Melayu. & 4.07 & 0.926 \\
\hline Purata & $\mathbf{4 . 1 9 9}$ & $\mathbf{0 . 7 0 5}$ \\
\hline
\end{tabular}

\section{Motivasi Intrinsik Murid Melanau Dalam MempelajariBahasa Melayu}

Jadual 7 menunjukkan analisis terperinci tentang item motivasi intrinsik murid Melanau terhadap bahasa Melayu. Daripada analisis yang dibuat didapati min dan sisihan piawai keseluruhan yang ditunjukkan ialah $3.814(\mathrm{~m}=3.814)$ dan $0.729(\mathrm{sp}=0.729)$ dan ia berada pada tahap tinggi. Min yang tertinggi ialah 4.40 dan berada pada tahap yang sangat tinggi dengan sisihan piawai 3.316 iaitu $44.2 \%$ responden kajian mengatakan bahawa mereka selalu berusaha bersungguh-sungguh mempelajari bahasa Melayu. Ini menunjukkan bahawa mereka mempunyai motivasi intrinsik yang sangat tinggi dalam mempelajari bahasa Melayu.

JADUAL 7 Taburan min bagi item motivasi intrinsik murid Melanau mempelajari bahasa Melayu

\begin{tabular}{lcc}
\hline \multicolumn{1}{c}{ Item } & Min & $\begin{array}{c}\text { Sisihan } \\
\text { Piawai }\end{array}$ \\
\hline 15. Saya segera menyiapkan tugasan Bahasa Melayu. & 3.70 & 0.880 \\
16. Saya menyiapkan tugasan bahasa Melayu dalam masa yang singkat. & 3.29 & 0.893 \\
17. Saya aktif dalam aktiviti pembelajaran Bahasa Melayu. & 3.66 & 0.943 \\
18. Saya memperuntukkan masa yang lebih belajar Bahasa Melayu. & 3.45 & 0.888 \\
19. Saya seronok belajar Bahasa Melayu. & 4.13 & 0.867 \\
20. Belajar Bahasa Melayu telah menjadi hobi saya. & 3.59 & 1.052 \\
21. Saya minat belajar mata pelajaran Bahasa Melayu. & 4.02 & 0.915
\end{tabular}




\begin{tabular}{lll} 
22. Saya berusaha bersungguh-sungguh mempelajari Bahasa Melayu. & 4.40 & 3.316 \\
23. Saya memberikan tumpuan sepenuhnya dalam pembelajaran Bahasa Melayu. & 3.93 & 0.875 \\
24. Saya berpuas hati menyelesaikan tugasan Bahasa Melayu. & 3.97 & 0.899 \\
25. Saya bekerjasama menyelesaikan tugasan berkumpulan Bahasa Melayu. & 3.95 & 0.903 \\
26. Saya bercita-cita melanjutkan pelajaran dalam bidang Bahasa Melayu. & 3.69 & 1.173 \\
\hline Purata & $\mathbf{3 . 8 1 4}$ & $\mathbf{0 . 7 2 9}$ \\
\hline
\end{tabular}

\section{Motivasi Ekstrinsik Murid Melanau Dalam Mempelajari Bahasa Melayu}

Analisis terperinci tentang item motivasi ekstrinsik murid Melanau terhadap bahasa Melayu seperti pada Jadual 8 menunjukkan min dan sisihan paiwai keseluruhan ialah $3.870(\mathrm{~m}=3.870)$ dan $0.637(\mathrm{sp}=0.637)$ dan ia berada pada tahap tinggi. Min yang tertinggi ialah 4.49 berada pada tahap yang sangat tinggi dengan sisihan piawai 0.719 iaitu $59.5 \%$ responden kajian mengatakan bahawa mereka selalu berpandangan bahasa menguasai bahasa Melayu membolehkan mereka berkomunikasi dengan kaum lain. Ini menunjukkan bahawa mereka mempunyai motivasi ekstrinsik yang sangat tinggi dalam mempelajari bahasa Melayu.

JADUAL 8 Taburan min bagi item motivasi ekstrinsik murid Melanau mempelajari bahasa Melayu

\begin{tabular}{|c|c|c|}
\hline Item & Min & $\begin{array}{l}\text { Sisihan } \\
\text { Piawai }\end{array}$ \\
\hline 27. Saya belajar Bahasa Melayu mengikut jadual. & 3.29 & 1.105 \\
\hline 28. Saya menyiapkan tugasan Bahasa Melayu mengikut jadual. & 3.25 & 1.009 \\
\hline $\begin{array}{l}\text { 29. Saya memberi tumpuan kepada soalan Bahasa Melayu yang dijangka keluar } \\
\text { dalam peperiksaan. }\end{array}$ & 4.05 & 0.943 \\
\hline 30. Saya mempunyai kelebihan jika menguasai Bahasa Melayu. & 3.60 & 0.942 \\
\hline $\begin{array}{l}\text { 31. Pujian guru kepada saya membuatkan saya bersemangat mempelajari Bahasa } \\
\text { Melayu. }\end{array}$ & 3.92 & 0.989 \\
\hline $\begin{array}{l}\text { 32. Saya mencapai keputusan yang baik dalam peperiksaan Bahasa Melayu dan } \\
\text { guru memberikan hadiah galakan kepada saya. }\end{array}$ & 3.15 & 1.061 \\
\hline $\begin{array}{l}\text { 33. Menguasai Bahasa Melayu membolehkan saya membaca majalah berbahasa } \\
\text { Melayu. }\end{array}$ & 4.11 & 0.942 \\
\hline 34. Menguasai Bahasa Melayu membolehkan saya faham novel dan filem Melayu. & 4.23 & 0.917 \\
\hline $\begin{array}{l}\text { 35. Menguasai Bahasa Melayu membantu saya mendapat keputusan ujian yang } \\
\text { baik. }\end{array}$ & 4.23 & 0.867 \\
\hline \multirow{2}{*}{$\begin{array}{l}\text { 36. Menguasai Bahasa Melayu membantu saya mendapat pekerjaan yang baik. } \\
\text { 37. Menguasai Bahasa Melayu membolehkan saya berkomunikasi dengan kaum } \\
\text { lain. }\end{array}$} & 4.24 & 0.863 \\
\hline & 4.49 & 0.719 \\
\hline Purata & 3.870 & 0.637 \\
\hline
\end{tabular}

\section{PERBINCANGAN}

\section{Sikap Terhadap Bahasa Melayu}

Dapatan kajian menunjukkan murid Melanau bersikap positif terhadap penutur bahasa Melayu kerana responden kajian mengatakan bahawa mereka selalu berasa seronok berkenalan dengan orang Melayu. Responden kajian juga mengatakan bahawa mereka selalu mempunyai perasaan ingin mempunyai hubungan dengan orang Melayu. Hal ini menunjukkan bahawa mereka mempunyai sikap integratif yang tinggi terhadap bahasa Melayu. Responden kajian juga mengatakan bahawa mereka selalu bersungguhsungguh belajar bahasa Melayu dan sikap mereka ini mempamerkan minat yang sangat tinggi terhadap bahasa Melayu.

Dapatan ini memperlihatkan bahawa sikap murid Melanau dalam pembelajaran bahasa Melayu sebagai bahasa kedua adalah tinggi dan sangat tinggi. Dapatan ini menyokong kajian oleh Abdul Rahim dan Mohd Sharifudin (2014) yang menunjukkan majoriti murid Orang Asli dalam kajian mereka 
mempunyai sikap positif terhadap bahasa Melayu. Dapatan kajian mereka memberikan gambaran bahawa murid-murid mempunyai sikap yang positif dalam diri masing-masing ketika mempelajari bahasa Melayu. Kajian Abdullah (2004) juga menyokong dapatan ini di mana murid-murid Dusun mempunyai sikap yang positif terhadap bahasa Melayu.

Namun, kajian ini bertentangan dengan kajian yang dijalankan oleh Zamri dan Mohamed Amin Embi (2006) yang mendapati murid bukan Melayu mempunyai sikap yang negatif dan kurang berminat untuk mempelajari bahasa Melayu. Demikian juga kajian yang dilakukan oleh Mohamad Yazid (2015), serta Zamri, Kamaliah Ayu dan Wan Muna Ruzanna (2016). Kedua-dua kajian ini mengkaji murid Cina yang mempelajari bahasa Melayu. Antara hasil kajian mereka ialah murid-murid Cina ini kurang berminat mempelajari bahasa Melayu. Mereka hanya mempelajari bahasa Melayu untuk lulus dalam ujian sahaja kerana terpaksa mengambilnya.

Rumusannya, dari segi sikap terhadap bahasa Melayu, murid-murid Melanau ini masih mempunyai sikap postif terhadap bahasa Melayu. Mereka mengakui akan kepentingan bahasa Melayu sebagai bahasa ilmu, bahasa rasmi dan bahasa kebangsaan di negara Malaysia. justeru, mereka perlu menguasainya dengan baik. Dengan menguasainya, mereka akan mudah untuk berkomunikasi dengan rakan-rakan penutur bahasa Melayu.

\section{Motivasi Terhadap Bahasa Melayu}

Selain itu, motivasi intrinsik murid Melanau terhadap bahasa Melayu juga berada pada tahap yang sangat tinggi. Responden kajian mengatakan bahawa mereka selalu berusaha bersungguh-sungguh mempelajari bahasa Melayu. Hal ini menunjukkan bahawa mereka mempunyai motivasi intrinsik yang sangat tinggi dalam mempelajari bahasa Melayu. Di samping itu, mereka mempunyai motivasi ekstrinsik yang sangat tinggi dalam mempelajari bahasa Melayu kerana mereka selalu berpandangan bahawa menguasai bahasa Melayu membolehkan mereka berkomunikasi dengan kaum lain. Dapatan ini menyokong kajian oleh Siti Salwah dan Jamaluddin (2013) yang menyatakan bahawa motivasi murid peralihan yang terdiri daripada kaum Cina dan India mempelajari bahasa Melayu sebagai bahasa kedua adalah tinggi motivasi mereka apabila wujud ganjaran untuk setiap aktiviti yang berjaya dilakukan oleh mereka dalam pembelajaran bahasa kedua. Kajian oleh Jerie dan Zamri (2010) terhadap murid Iban di daerah Kanowit, Sarawak berkaitan sikap dan motivasi mempelajari bahasa Melayu sebagai kedua juga menyokong kajian ini. Dapatan kajian mereka menunjukkan murid Iban di daerah Kanowit, Sarawak mempunyai sikap yang positif dan motivasi yang tinggi sewaktu mempelajari bahasa Melayu sebagai kedua. Secara tidak langsung, kedua-dua kajian ini menyokong kajian yang dijalankan. Kajian ini juga menyamai kajian yang dijalankan oleh Khairul Nizam (2017) dan Felecia (2017) yang menyatakan murid-murid peribumi di Sabah dan Sarawak mempunyai motivasi yang tingghi ketika belajar bahasa Melayu.

Namun, dapatan kajian Abdul Rasid (2010) dan Mohamad Yazid (2017) terhadap murid Cina bertentangan dengan kajian ini, apabila dapatan kajian menunjukkan murid Cina kurang bermotivasi untuk mempelajari Bahasa Melayu kerana mereka merasakan Bahasa Melayu sebagai satu mata pelajaran yang susah dan mengelirukan. Mereka kurang berminat untuk mempelajari bahasa Melayu. Selain mempunyai persepsi negatif, mereka juga beranggapan bahawa bahasa Melayu tidak mempunyai nilai ekonomi berbanding bahasa Inggeris dan bahasa Mandarin. Atas dasar tersebut, murid-murid Cina ini kurang berminat mempelajari bahasa Melayu.

Rumusannya, walaupun terdapat segelintir murid yang kurang bermotivasi mempelajari bahasa Melayu, namun secara keseluruhannya, murid-murid Melanau ini bermotivasi mempelajari bahasa Melayu. Mereka menyedari akan kepentingan bahasa Melayu yang merupakan bahasa kebangsaan. Dengan menguasainya, murid-murid Melanau ini akan bermotivasi untuk belajar bahasa Melayu dan seterusnya dapat berkomunikasi dengan baik dalam situasi rasmi dan tidak rasmi.

\section{IMPLIKASI KAJIAN}

Kajian tentang sikap dan motivasi murid-murid bukan Melayu bukanlah suatu yang baharu dalam konteks PdPc bahasa Melayu. Sudah banyak kajian dilakukan seperti yang dijalankan oleh Abdullah (2004) untuk murid Dusun, Jerie (2009) untuk murid Iban, Abdul Rasid (2011) untuk murid Cina, Abdul Rahim dan 
Mohd Sharifudin (2014) untuk murid Orang Asli, Mohamad Yazid (2016) untuk murid Cina, Khairul Nizam (2017) untuk murid Bajau, Felecia (2017) untuk murid Iban dan lain-lain pengkaji bahasa. Namun demikian, kajian yang dijalankan ini merupakan suatu yang baharu dalam konteks pedagogi bahasa Melayu. Setakat pembacaan literatur yang dijalankan mendapati belum ada satu kajian yang mengkaji bagaimana murid-murid Melanau belajar bahasa Melayu sebagai bahasa kedua mereka. Adakah mereka berminat dan bermotivasi belajar bahasa Melayu? Dapatan kajian menunjukkan mereka berminat, bermotivasi dan bersikap positif terhadap pembelajaran bahasa Melayu. Justeru, hasil kajian ini menyumbang dalam pendidikan bahasa Melayu di Malaysia.

Selain itu, kepentingan bahasa Melayu sebagai bahasa rasmi dan bahasa pengantar sangat penting untuk dikuasai oleh semua murid tanpa mengira kaum. Sebagai bahasa ilmu, bahasa Melayu perlu diajar dengan betul dan berkesan. Dapatan kajian ini menunjukkan bahawa murid-murid Melanau ini mempunyai sikap dan motivasi yang positif terhadap pembelajaran bahasa Melayu mereka. Murid Melanau perlu memanfaatkan pembelajaran di sekolah semaksimum mungkin agar sikap serta motivasi mereka dalam pembelajaran bahasa Melayu sebagai bahasa kedua meningkat. Murid Melanau juga perlu mempunyai keyakinan diri yang tinggi agar dapat menguasai bahasa Melayu dengan baik. Mereka harus bersikap positif dan bermotivasi tinggi dalam mempelajari bahasa Melayu agar pencapaian cemerlang dalam mata pelajaran wajib ini dapat dicapai.

Pihak sekolah dan guru perlu menyedari hakikat bahawa pembelajaran bahasa kedua dalam kalangan murid Melanau tidak hanya dilihat sebagai mata pelajaran akademik yang memenuhi tuntutan kurikulum, tetapi turut mempelajari budaya masyarakat yang menuturkannya. Sehubungan itu, dicadangkan agar penekanan lebih kepada kemahiran berbahasa dari segi komunikasi dan interaksi. Hal ini dapat dilakukan dengan mengadakan sesi perbincangan yang boleh meningkatkan kesedaran murid, misalnya perbincangan tentang budaya bahasa kedua yang akan meningkatkan pendedahan dan pemahaman tentang budaya masyarakat bahasa berkenaan.

Usaha menempatkan bilangan guru bahasa yang mencukupi di sekolah-sekolah terutama guru bahasa Melayu sangat penting dan bermakna dalam usaha meningkatkan pencapaian bahasa Melayu dan penguasaan bahasa Melayu. Kekurangan guru bahasa Melayu antara faktor kemerosotan pencapaian murid dalam mata pelajaran bahasa Melayu. Peranan guru sangat penting kerana guru merupakan pendorong sikap positif dan perangsang motivasi kepada murid. Oleh itu, usaha menambah bilangan guruguru terlatih mengikut opsyen bahasa Melayu merupakan satu tindakan utama sebagai usaha meningkatkan penguasaan bahasa Melayu dalam kalangan murid. Usaha memartabatkan bahasa Melayu merupakan langkah yang wajar kerana mampu meningkatkan tahap penguasaan bahasa Melayu terutama dalam kalangan murid bukan Melayu. Usaha ini juga merupakan tindakan yang positif kerana ia mampu memotivasikan murid, guru dan ibu bapa, akan betapa pentingnya penguasaan bahasa Melayu setanding dengan bahasa ilmu yang lain.

\section{KESIMPULAN}

Dapatan dan maklumat kajian ini menunjukkan betapa pentingnya bahasa Melayu dikuasai untuk menghadapi kehidupan mereka pada masa hadapan. Kebanyakan murid suka belajar bahasa Melayu kerana bahasa Melayu sangat penting dalam kehidupan seharian mereka sebagai murid. Oleh itu, berdasarkan dapatan kajian ini peranan guru bahasa Melayu sangat penting dalam usaha mempelbagaikan kaedah dan pendekatan dalam PdPc Bahasa Melayu. Teknik PdPc yang bersesuaian dengan pembelajaran abad ke-21 harus dikuasai oleh guru agar murid lebih bersikap positif dan minat terhadap bahasa Melayu. Sikap dan motivasi murid harus dipupuk dan dibentuk dalam setiap aktiviti PdPc bahasa Melayu si sekolah. Kajian ini sangat penting kepada murid, guru, dan pembuat dan pelaksana dasar.

Usaha memartabatkan bahasa Melayu merupakan langkah yang wajar kerana mampu meningkatkan tahap penguasaan bahasa Melayu terutama dalam kalangan murid bukan Melayu. Usaha ini juga merupakan tindakan yang positif kerana ia mampu memotivasikan murid, guru dan ibu bapa akan betapa pentingnya penguasaan bahasa Melayu setanding dengan bahasa ilmu yang lain. Kajian ini telah menyorot tentang sikap dan motivasi murid Melanau dalam pembelajaran bahasa Melayu sebagai bahasa kedua. Sikap dan motivasi merupakan dua aspek yang kompleks kerana kedua-duanya mengandungi unsur psikologi yang saling berkaitan tetapi bersifat individual dan masing-masing dibentuk oleh latar 
belakang responden dan pengalaman yang berbeza. Selain itu, sikap dan motivasi juga boleh berubah mengikut perkembangan persekitaran yang dilalui sama ada pada zaman kanak-kanak, pada alam persekolahan sehinggalah ke alam kerjaya.

Dalam kajian ini, murid-murid Melanau mempelajari bahasa Melayu sebagai bahasa kedua kerana mereka mempunyai sikap yang positif dan motivasi yang tinggi terhadap pembelajaran bahasa tersebut. Kajian ini hanya terbatas kepada dapatan yang berdasarkan sampel yang berkaitan dan mempunyai ciriciri yang hampir sama. Walau bagaimanapun, kajian ini diharap dapat memberi input dalam bidang penyelidikan selanjutnya dan dunia pendidikan khususnya.

\section{RUJUKAN}

Abdul Rahim Abu \& Mohd Sharifudin Yusop. (2014). Sikap kanak-kanak orang asli di bandar raya Kuala Lumpur terhadap penguasaan bahasa Melayu sebagai bahasa kedua. Jurnal Pendidikan Bahasa Melayu, 4(2), 57-66.

Abdul Rashid Jamian. (2011). Permasalahan pengajaran dan pembelajaran bahasa Melayu dalam kalangan murid Cina. Jurnal Pendidikan Bahasa Melayu, 1(1), 1-12.

Abdullah Musa. (2004). Sikap dan motivasi murid Dusun terhadap pembelajaran bahasa Melayu dan bahasa Inggeris sebagai bahasa kedua. Kertas Projek Sarjana Pendidikan yang tidak diterbitkan. Fakulti Pendidikan, Universiti Kebangsaan Malaysia, Bangi.

Felicia anak Kiai. (2017). Pengaruh sikap, minat dan motivasi dalam pembelajaran bahasa Melayu murid Iban daerah Kapit. Kertas Projek Sarjana Pendidikan yang tidak diterbitkan. Falkulti Pendidikan, Universiti Kebangsaan Malaysia.

Gardner. R. C. (1985). Social psychology and second language learning: The role attitudes and motivation. London: Edward Arnold.

Jerie anak Peter Langan \& Zamri Mahamod. (2011). Sikap dan motivasi murid Iban dalam mempelajari bahasa Melayu sebagai bahasa kedua. Jurnal Pendidikan Bahasa Melayu, 1(1), 13-25.

Kamiliah Ayu Ab. Ghani. (2015). Strategi pembelajaran bahasa Melayu dalam kalangan murid bukan Melayu. Kertas Projek Sarjana Pendidikan yang tidak diterbitkan. Fakulti Pendidikan, Universiti Kebangsaan Malaysia.

Kamsiah Abdullah. (2000). Sikap, penguasaan dan penggunaan Bahasa Melayu di Singapura. Singapura: Asas 50.

Khairul Nizam Mohamed Zuki. (2017). Sikap dan motivasi murid Bajau daerah Beluran dalam mempelajari bahasa Melayu sebagai bahasa kedua. Kertas Projek Sarjana Pendidikan yang tidak diterbitkan. Falkulti Pendidikan, Universiti Kebangsaan Malaysia.

Krejcie, R.V. \& Morgan, D.W. (1970). Determining sample size for research activities. Educational and Psychological Measurement, 30, 608-613.

Lembaga Peperiksaan Malaysia. (2015). Laporan Sijil Peperiksaan Malaysia 2015.Putrajaya: Kementerian Pendidikan Malaysia.

Mohamad Yazid Mohamad. (2016). Kekerapan penggunaan strategi pembelajaran bahasa Melayu dalam kalangan murid sekolah jenis kebangsaan cina. Kertas Projek Sarjana Pendidikan yang tidak diterbitkan. Fakulti Pendidikan, Universiti Kebangsaan Malaysia.

Sakeran. U. (1992). Research method for business: A skill building approach. Second Edition. New York: John Wiley and Son.

Siti Salwah Atan \& Jamaludin Badusah. (2013). Sikap dan motivasi murid peralihan dalam mempelajari bahasa Melayu sebagai bahasa kedua. Prosiding Seminar Serantau Pascasiswazah Pendidikan Bahasa Melayu \& Kesusasteraan Melayu Kali Kedua, 441-455. Bangi: Penerbit Fakulti Pendidikan Universiti Kebangsaan Malaysia.

Tschannen-Moran, M. \& Garies, C.R. (2004). Principle's sense of eficacy: assesing a promising construct. Journal of Educational Administration. 42 (5): 573-585.

Zamri Mahamod \& Mohamed Amin Embi. (2006). Kesalahan bahasa dalam penulisan karangan murid bukan Melayu: satu kajian kes. Dlm. Zamri Mahamod (Pnyt). Psikolinguistik dalam Pengajaran dan Pembelajaran Bahasa Melayu, 214-262. Shah Alam: Karisma Publication Sdn Bhd.

Zamri Mahamod, Kamilah Ayu Ab. Ghani \& Wan Muna Ruzanna Wan Mohamad. (2016). Penggunaan strategi pembelajaran bahasa Melayu dalam kalangan murid cina berdasarkan sikap dan kemahiran bahasa. Jurnal Pendidikan Bahasa Melayu, 6(1), 38-51.

Zamri Mahamod, Ruslin Amir \& Mohamed Amin Embi. (2015). Kepelbagaian pelajar dan perbezaan pembelajaran. Kuala Lumpur: Dewan Bahasa dan Pustaka.

Zamri Mahamod. (2016). Psikolinguistik dan pengajaran bahasa. Bangi: Penerbit Fakulti Pendidikan, Universiti Kebangsaan Malaysia. 